\title{
EDITORIAL
}

\section{Call for Stories of On-the-Ground Innovations in Primary Health Care}

\author{
Kurt C. Stange, MD, PbD, Editor \\ John J. Frey III, MD, Associate Editor
}

Ann Fam Med 2016;14:502. doi: 10.1370/afm.2001.

$\mathrm{T}$ This is a revolutionary time in primary health care. Groundbreaking advances are being implemented in a variety of settings.

Although most of the revolution is invisible through the usual lenses of measurement, research, and publication, important advances are taking place. Some advances address integrating, personalizing, or prioritizing health care or health promotion for the individual, family, or community. Others are about new partnerships, uses of technology, or novel ways of developing relationships. Many advances actively rail against current structures that devalue what is most important about primary care. Some quietly tie into timeless values and actions of healers and the personal physician. Some innovations involve reinventing formerly useful ways of working, but in a new era. The most compelling advances have the potential to be transportable to other settings and scalable to broader contexts.

The Annals of Family Medicine seeks examples of innovations that make a difference in primary health care. These examples may be in primary care practice, the empowerment of people and communities, or in yet unexplored domains. We want to bring these compelling experiences to readers for both their local application and their ability to inspire other ideas.
We invite innovators to send a brief description of their innovation to Innovation-Stories@case.edu. This brief description should include the following.

- In approximately one-half page, describe:

$\circ$ the idea, and what makes it innovative

$\circ$ who is using it

- what has been learned so far

- its potential impact on clinicians, patients, or communities

- the story behind the idea, eg, where it originated, why it is catching on now, any comparable or similar innovations occurring elsewhere, etc

- Please include your name, email address, and telephone number.

The Annals editors will work with the authors of the most promising submissions to find an effective way of sharing their innovation stories. Publication format will depend on the volume and quality of applications we receive and might include publication in a regular issue, an ongoing feature of Annals of Family Medicine, or in a supplement showcasing these innovations.

Many innovators are too busy trying to solve problems on the ground to label themselves as innovators. We ask readers to share this call widely and personally with those who are inventing the future. We are seeking primary health care pioneers. 